Citing this article: Jaspal, R. (2019). Parental reactions to British South Asian young men who identify as gay. Journal of GLBT Family Studies.

https://doi.org/10.1080/1550428X.2019.1684412

Running head: Parental reactions to coming out

Title: Parental reactions to British South Asian young men who identify as gay

Author: Rusi Jaspal, De Montfort University, Leicester, UK.

Abstract: British South Asian gay men may face significant psychological distress as a result of parental rejection due to their sexual orientation. This study is the first in the UK to examine parental reactions to British South Asian young men who come out as gay. Twelve British South Asian parents participated in 'conversational enquiries', a series of unstructured interviews, which explored their experiences of having a son come out as gay. The data were analyzed using qualitative thematic analysis and identity process theory. Three themes are described. First, threats to self-esteem and continuity associated with having a gay son are described. Second, it is shown that parents favored and, in some cases, continue to favor denial of the fact, or implications, of their son's coming out. Third, parents may deem isolation from significant others to be necessary in order to avoid social stigma due to their sons' sexual orientation. Recommendations are offered for supporting the parents of British South Asian young men who identify as gay.

Keywords: identity; coping; coming out; parents; British South Asians

Address for correspondence: Professor Rusi Jaspal, Faculty of Health and Life Sciences, De Montfort University, Leicester LE1-9BH, United Kingdom. Tel: +44 (0)116-257-7109. Email: rusi.jaspal@,cantab.net

Author biography: Professor Rusi Jaspal is Pro Vice-Chancellor (Research) and Chair in Psychology and Sexual Health at De Montfort University, Leicester, UK. His current research focuses upon identity processes and identity threat, particularly among ethnic, religious and sexual minorities. Rusi Jaspal is the author of The Social Psychology of Gay Men (Palgrave, 2019) and of Enhancing Sexual Health, Self-Identity and Wellbeing among Men Who Have Sex With Men: A Guide for Practitioners (Jessica Kingsley Publishers, 2018) and co-editor (with Dame Glynis Breakwell) of Identity Process Theory: Identity, Social Action and Social Change (Cambridge University Press, 2014). 


\title{
Parental reactions to British South Asian young men who identify as gay
}

\begin{abstract}
British South Asian gay men may face significant psychological distress as a result of parental rejection due to their sexual orientation. This study is the first in the UK to examine parental reactions to British South Asian young men who come out as gay. Twelve British South Asian parents participated in 'conversational enquiries', a series of unstructured interviews, which explored their experiences of having a son come out as gay. The data were analyzed using qualitative thematic analysis and identity process theory. Three themes are described. First, threats to self-esteem and continuity associated with having a gay son are described. Second, it is shown that parents favored and, in some cases, continue to favor denial of the fact, or implications, of their son's coming out. Third, parents may deem isolation from significant others to be necessary in order to avoid social stigma due to their sons' sexual orientation. Recommendations are offered for supporting the parents of British South Asian young men who identify as gay.
\end{abstract}

Keywords: identity; coping; coming out; parents; British South Asians

\section{Introduction}

For many gay men, coming out to their parents is a psychologically significant event. Parents play an important role in one's identity development and socialization. Many gay men seek support from their parents in relation to their sexual identity. As parents are deemed to be a source of emotional safety, gay men hope to be understood and supported when they come out as gay. Yet, they may be disappointed and face identity threat if such support is not received. Conversely, the parents of young men who come out as gay may themselves face challenges in accepting their sons' sexual identities. Some have internalized stigmatizing stereotypes of homosexuality. They too may require support in order to accept their sons' sexual identities in a way that is socially and psychologically beneficial to them and to their sons. Social attitudes towards homosexuality are improving, potentially making it easier for young men in Western industrialized societies to come out and for their parents to accept their coming out (McCormack, 2012). However, this is unfortunately not the case for all ethnic and religious communities in Britain. 
British South Asians constitute a significant ethnic minority group in Britain - the 2011 UK Census revealed an estimated population of 4.2 million. Empirical research suggests that the parents of British South Asian gay men struggle to understand and accept the sexual orientation of their gay sons (e.g. Jaspal \& Cinnirella, 2010; Jaspal \& Siraj, 2011). This can be attributed to the collectivist cultural orientation, strong religious norms, and unaddressed homophobic stigma in British South Asian communities. The study described in this article is the first in the UK to examine parental reactions to British South Asian young men who come out as gay. Through the lens of identity process theory, first, the impact for psychological wellbeing of having a son come out as gay is explored; second, the coping strategies favored by British South Asian parents in response to the sons' coming out are investigated; and, third, some tentative recommendations are made for supporting the parents of British South Asian gay men.

\section{Identity process theory}

This article draws upon identity process theory (Jaspal \& Breakwell, 2014), which is an integrative social psychological theory of identity construction, threat and coping. The theory can provide a useful heuristic lens for understanding how British South Asian parents may be affected psychologically by their sons' coming out as gay, and how they attempt to safeguard psychological wellbeing in the face of this event.

According to identity process theory, identity construction is constructed through two universal processes.The assimilation-accommodation process refers to the absorption of new information in the identity structure (e.g. 'my son is gay') and to the adjustment which takes places in order for it to become part of the structure (e.g. 'my son is gay so my family's relationship with our cultural community may need to change'). The evaluation process confers meaning and value upon the contents of identity (e.g. 'being gay is negative and sinful').

These processes are guided by identity principles, which 'specify the end states that are desirable for identity' (Breakwell, 1986, p. 24). These include self-esteem, self-efficacy, continuity, distinctiveness and coherence. These principles are cross-culturally relevant and there is no reason to assume that they would not be important to British South Asians (Vignoles, 2014). When the identity principles are abrogated as a result of changes in one's social context, identity is threatened, which is aversive for psychological wellbeing. For instance, due to the religiously-based stigma of homosexuality, having a son come out as gay may challenge continuity and self-esteem among parents who themselves may believe that 
this is a sin. In response to identity threat, the individual will attempt to deploy strategies for coping with, or for reducing the negative impact of, the threat. A coping strategy is defined as 'any activity, in thought or deed, which has as its goal the removal or modification of a threat to identity' (Breakwell 1986, p. 78). Coping strategies can function at intrapsychic, interpersonal and/ or intergroup levels.

\section{British South Asian gay men}

There is now a significant body of research into the identities and experiences of British South Asian gay men, much of which highlights the psychological distress that many face as a result of rejection from significant others due to their sexual orientation (Jaspal \& Cinnirella, 2010, 2012; Jaspal, Lopes \& Rehman, 2019; Jaspal \& Siraj, 2011; Yip, 2004). Individuals face a multi-faceted stigma which, for many, originates from their religious group (Yip, 2007). Most British Indians are, at least nominally, of Hindu or Sikh faith (Ghuman, 2003). Neither Hinduism nor Sikhism officially prohibits homosexuality and, thus, homophobia within these communities can more accurately be attributed to 'cultural' rather than theological factors (Jaspal, 2012). Conversely, Islam, which is the religion of most British Pakistanis, generally takes a negative stance on homosexuality and is opposed to Western conceptualizations of homosexuality in the sense of 'coming out' as exclusively gay (Duran, 1993). Crucially, religion may be drawn upon by individuals in order to substantiate their beliefs about homosexuality.

Previous research has focused on coming out (Jaspal \& Siraj, 2011), interpersonal relations on the gay scene (Bassi, 2008) and the cultural expectation of heterosexual marriage (Jaspal, 2014). Much of this work highlights the high risk of identity threat among British South Asian gay men. In one of the first studies of this population, Bhugra (1997) noted feelings of regret, self-deprecation and self-hatred among many of his participants, given the 'traumatic discrepancy' between being Asian and gay. He attributed this traumatic discrepancy to individuals' attempts to construct 'a coherent sense of self from the two identities he seeks to attain: Asian and gay' (p. 556), alluding to threats to identity coherence (Jaspal \& Cinnirella, 2010). Homophobia from one's valued ethnic and religious ingroups can severely undermine the self-esteem principle of identity - individuals may fail to derive a positive self-conception on the basis of their gay identity (Yip, 2007).

The present article builds on this research by providing insight into parental reactions to British South Asian men who come out as gay. There is no research into how the identities and psychological wellbeing of British South Asian parents may be affected by their sons' 
coming out - from the perspective of parents themselves. Focusing on the identities and psychological wellbeing of British South Asian parents is important for at least two reasons: first, parents may require support in order to cope effectively with their son's coming out and, second, parents are better positioned to support their children when they themselves are supported and empowered to do so (Savin-Williams \& Dube, 1998).

The study focuses on gay men in particular for two principal reasons. First, existing research suggests that gay men face especially high levels of stigma in British South Asian communities due partly to the religious taboo of male homosexuality in these communities (e.g. Jaspal, 2012). It is therefore foreseeable that the parents of gay men face distinct social psychological challenges from those of the parents of lesbian women, for instance. Second, in South Asian cultures (and indeed in most collectivist cultures), there is a patriarchal expectation that male offspring will enter into a heterosexual marriage, produce offspring, and provide continuity to the family lineage (Ghuman, 2003). This does not apply to lesbian daughters in quite the same way, further reiterating the hypothesis of distinct challenges associated with having a gay son.

\section{Empirical research into parental reactions}

Many gay men report social psychological difficulties in relation to coming out to their parents. In one study (D’Augelli, Grossman \& Starks, 2008), 71\% of the young people perceived their parents' reaction to their coming out to be negative. Gay men generally express a preference to self-disclose to female friends in the first instance from whom they seek support before taking the significant step of coming out to their parents. A negative parental reaction can have negative long-term effects for gay men - not least for their future personal relationships.

Some parents believe that coming out as gay is the result of bad parenting and attribute their child's sexual orientation to an adverse childhood event, which can lead to selfblame. Some elect a strategy of 'loving denial' (see Livingston \& Fourie, 2016), which refers to knowledge, but lack of acknowledgement, of their child's sexual identity. This essentially silences the topic without resolving the issues that surround it. This strategy can superficially safeguard the parent-child relationship by downplaying a controversial topic but implicitly signals parental dismay at the child's sexual orientation and their preference to avoid acknowledging it. Such attributional styles and coping strategies can further stigmatize the child's sexual orientation, thereby causing tension in parent-child relations. 
D'Amico, Julien and Chartrand (2015) found that parental support of their child's sexual orientation, parental attempts to control (or change) their child's sexual orientation, and parental struggles to accept their child's sexual orientation all have distinct implications for young gay men's identity development and psychological adjustment. It is noteworthy that not all parents are necessarily aware of, or understand, homosexuality. As Jaspal (2010) has argued, British South Asian parents may hold negative views of homosexuality and have little first-hand contact with gay people. This can make it difficult for them to react favorably to their own child's coming out.

Gay men are at disproportionately high risk of suicidal ideation compared to their heterosexual counterparts, with some research even suggesting that the gap in prevalence has been underestimated between heterosexuals and sexual minorities (e.g. Salway, Ploderl, Liu \& Gustafson, 2019). D’Augelli et al. (2005) found that gay men who report greater parental psychological abuse in childhood (possibly as a result of sexual identity disclosure) were more likely to have attempted suicide than those who do not. Moreover, those who reported being considered by their parents to be gender atypical and those whose parents discouraged gender atypical behavior were more likely to have attempted suicide. Studies of this kind highlight the severity of early rejection in childhood and the enduring, potentially lifethreatening consequences in adulthood.

Given that parental acceptance of their child's sexual identity is associated with several positive psychological and interpersonal outcomes in gay men, such as higher selfcompassion and lower internalized homophobia (Gertler, 2014), it is important to identify the factors that are might increase the likelihood of parental acceptance. In their study of 72 gay men, Willoughby, Malik and Lindahl (2006) found that gay men who described their families as cohesive, adaptive and authoritative perceived their parents' reaction to their coming out as less negative than those whose families were disconnected, rigid and authoritarian. These data suggest that a positive family structure is associated with a better coming out experience and, thus, better interpersonal relations in adulthood.

\section{The present study}

While there is a body of research into coming out from the perspective of British South Asian gay men and another focusing on parental reactions to coming out in the general population, there are no data on British South Asian parental reactions to coming out. This study addresses this gap in knowledge by providing qualitative data on identity, wellbeing and coping among parents - from their perspective. These data can in turn be utilized to 
develop more effective support mechanisms for the parents of British South Asian men who come out as gay.

\section{Method}

\section{Participant selection}

Twelve British South Asian parents participated in an unstructured interview study of the experience of having a son come out as gay. This sample size was deemed appropriate in view of the method of data collection, namely unstructured interviews which lasted several hours and generated large volumes of qualitative data. Following best practice for qualitative research (Lyons \& Coyle, 2007), the principal objective was to provide rich and multi-faceted insight into parental reactions, identities and experiences, rather than empirical generalizability. Each set of participant notes was analyzed immediately after data collection. Data saturation occurred after the tenth interview and two additional interviews were conducted which yielded very similar themes (Saunders et al., 2018). At this point, further data collection ceased. Participants were aged between 52 and $67(\mathrm{M}=59.6, \mathrm{SD}=4.9)$. Initial participants were recruited from within the researcher's own social circles. The researcher contacted acquaintances whose parents might be eligible to participate in this study, several of whom agreed to outline the study to their parents. A small number of participants was recruited using a snowball sampling strategy. In total, 12 individuals gave consent to participate in the study and did so.

Seven participants were women and 5 were men. Participants were recruited in Derby and West London, UK. Six were born in India and 6 in Pakistan. All of them had immigrated to the UK in their 20s, which for most participants was in the 1970s or 1980s. Participants had raised their children in the UK, who were thus second generation British South Asians. Six participants were employed, 3 were retired, and 3 of the female participants described themselves as housewives. Four interviewees reported having degree-level qualifications; 3 college-level qualifications; and 5 reported no formal education.

The notion of 'coming out' must be understood in the broadest sense possible. Coming out is not necessarily a discrete event whereby one discloses one's sexual identity to another individual but, in most cases, is complex and multifarious. First, coming out may occur in phases with details about one's identity being shared incrementally. Second, it may be occur various times - possibly in the face of denial from one's parents. Third, there are different degrees of 'outness' - some people are 'out' to everyone while others limit their sexual identity disclosure to a limited number of individuals. 
In this study, parents learned of their sons' sexual orientation in various ways - some reported having a clear discussion about their sons' sexual orientation, and others came to learn of it in less direct ways. In some cases, the initial discussion about sexual orientation was curtailed and silenced, although the key information about their sons' sexual orientation was communicated. Therefore, coming out must be viewed as in terms of a spectrum, rather than a dichotomy. In any case, participants described the initial coming out 'event' (that is, the first subjectively significant event, such as a gay magazine being found in one's bedroom and a subsequent conversation about sexuality) as having taken place between 3 and 7 years ago, with varying levels of acknowledgement and discussion since that initial event.

\section{Data generation}

The interviewer was an ethnic ingroup member with an understanding of participants' ethnic and religious identities and their heritage languages. This led to the (correct) assumption that the researcher was already familiar with the norms, values and representations associated with participants' identities. Participants were unaware of, and did not enquire about, the sexual identity of the interviewer. Some of the interviewees were personally acquainted with the interviewer (given that initial participants were recruited from within his own social circles). However, approximately half of the participants were not acquainted with them and, thus, some rapport-building was necessary in order to generate data for this study. Given the sensitivity surrounding the topic of coming out for British South Asians and the differing levels of acceptance of homosexuality in this population, a flexible interview design was deemed necessary.

First, it was made clear to participants that none of the interviews would be voicerecorded and that extensive notes would be taken during the interviews. This was deemed necessary as several participants felt uneasy about involuntary disclosure of their sons' sexual orientation and this was raised as a concern by the researcher's acquaintances who signposted their parents to the study. It is noteworthy that a similar method of (non-audio recorded) data collection has been used successfully in other empirical research (e.g. Anderson, 2010).

Second, each interview took place over several hours and followed some of the norms of ethnography. For instance, the interviewer spent time in the homes and environments of the interviewees posing questions and initiating relevant discussions during the course of their time together. Some of these discussions occurred with both parents present and others with just one parent. Five of the interviews were conducted in Punjabi which the interviewer speaks fluently. The interactions with participants are best described as 'conversational 
enquiries' occurring in naturalistic settings, rather than as formal one-to-one interviews.

Third, there was no specific interview guide but rather the interviews were largely unstructured with some clearly defined topics which the researcher endeavored to explore at some point during the conversational enquiries. These topics included their son's coming out event, the feelings associated with this, perceptions of homosexuality, quality of relationship with their gay son, and quality of relationship with relevant communities. The topic guide was constructed on the basis of extensive research into the identities and experiences of British South Asian gay men, some of which has been cited above (e.g. Jaspal \& Cinnirella, 2010). Other topics which arose during the course of the conversational enquiries were also considered as part of the research process.

Fourth, during the course of the conversational enquiries, extensive notes were taken to capture the content, tone, language and other aspects of the exchanges with participants. The vast majority of the notes were written in English but some key phrases were noted in Punjabi and subsequently translated for presentation in this article. An attempt was made to note down verbatim key participant observations but, given that the interviews were not audio-recorded and then transcribed, the priority was to capture the essence of participants' accounts. A key advantage of this mode of data generation is that the researcher was able to capture ethnographic data, such as the social context in which a particular remark was made, the presence of other people, reactions to observations made by other people, and the conversational context in which particular observations arose. All of these observations formed part of the data set which was subjected to thematic analysis.

\section{Analytic approach and procedure}

The qualitative data (that is, notes taken during the conversational enquiries) were analyzed using an inductive, interpretative variant of thematic analysis, which has been described as 'a method which works both to reflect reality, and to unpick or unravel the surface of 'reality', providing 'a method for identifying, analysing and reporting patterns (themes) within data' (Braun \& Clarke, 2006). It is a flexible qualitative technique that allows the analyst to identify key perceptions of, and meanings attributed to, a particular phenomenon. This approach can shed light on the subjective perceptual processes associated with participants' attempts to make sense of their sons' coming out as gay. Moreover, its idiographic mode of enquiry facilitates in-depth exploration of how each individual experienced their son's coming out, the meanings they attributed to this event, and how the event has subsequently been assimilated and accommodated in identity. 
The interview notes were read repeatedly in order for the analyst to acquire familiarity with the data. The earliest stage of analysis was initiated during data collection, since the researcher noted preliminary impressions and interpretations. During each reading of the interview notes, further analytic impressions and interpretations were developed. These more developed codes included participants' beliefs and attitudes, reported experiences, particular forms of language, and apparent contradictions and patterns within the data. Tenets of identity process theory were drawn upon in order to conduct the preliminary analysis. For instance, observations concerning the identity processes and principles and coping strategies were made at this stage.

Subsequently, these initial codes were collated into potential themes with subsequent higher-level interpretative work. The list of themes was reviewed rigorously against the interview notes to ensure their compatibility and numerous interview extracts were listed against each corresponding theme. At this stage, specific participant quotes included in the interview notes, which were considered representative of the themes, were selected for presentation in this article. It is worth reiterating that participant quotes below may not be verbatim as they are extracted from notes made during the conversational enquiries with participants. However, every effort has been made to capture the content and tone of participants' observations. Finally, three superordinate themes, which reflected the analysis, were developed and ordered into a coherent narrative structure. Each quote indicates the participant's pseudonym, their religion, and their ethnicity.

\section{Results}

In this section, the following three themes are described: (1) Threats to identity associated with coming out, (2) Denial as a strategy for coping with coming out, and (3) Isolation for avoiding social stigma.

\section{Threats to identity associated with coming out}

The data clearly demonstrated that parents construed their position as the parents of gay men as a threat to identity. Various principles of identity were susceptible to threat as a result of their occupancy of this stigmatized social position.

I just thought I had failed as a mother and failed in my duty as a good Muslim. It had a bad impact on me. I felt disgusted with him and also with myself. And I was alone in this feeling because I couldn't tell my husband anything or my other children even.

(Nazreen, female, Muslim, Pakistani) 
Fundamentally, Nasreen construed her son's coming out as a threat to continuity because this unexpected event represented a rupture between past, present and future. Nasreen had initially described the stability of her identity as a 'good' Muslim mother but her son's coming out undermined her self-perception both as a good mother and as a good Muslim. Nasreen reported a sense of personal responsibility in relation to her son's sexual identity development and believed that she had failed in her religious duty to raise a heterosexual son. Thus, the perception of homosexuality as a sin was extended and generalized to her sense of self.

Clearly, this perception of personal failure and religious sin induced threats to selfesteem as she reported feeling 'disgusted' with herself but it also compromised her relationship with her son with whom she also 'felt disgusted'. Given the importance of the family and indeed family honor in the identities of British South Asians (Ghuman, 2003), it is plausible that the disgust evoked by her son would undermine her own self-esteem. In view of the stigma and consequential silencing of homosexuality in family and ethno-cultural contexts, Nasreen felt unable to seek social support from significant others, such as her husband and her other children. Indeed, she did not feel able to disclose this information (namely that her son was gay) to other members of her family due to fears of negative reactions and blame. Nasreen's account highlighted the social, interpersonal and psychological complexities surrounding the assimilation-accommodation of one's son's sexual orientation within one's sense of self.

As indicated in the accounts of both Nasreen and Paramjit, the perception of sin and wrongdoing - rooted largely in religious doctrine - was pervasive in the participant sample:

I wanted my son back. I couldn't look at him in the same way. I just felt he is doing something terrible in the eyes of God. I couldn't accept his new lifestyle. (Paramjit, female, Sikh, Indian)

Due to the perceived negativity surrounding her son's 'new lifestyle', that is, his identity as a gay man, Paramjit came to believe that her son was engaging in wrongdoing, described as 'something terrible'. She and others made vague remarks about the religious prohibition of homosexuality without necessarily substantiating them. As indicated earlier in this article, Sikh teachings do not prohibit homosexuality. Muslim participants did, however, make reference to both the Koran and Ahadith (statements and teaching attributed to the Prophet Mohammed) to argue against homosexuality. As reiterated in Nasreen's account, the perception of sin and wrongdoing compromised her relationship with her son due to the introduction of negative change. Paramjit felt unable to regard her son as she had done 
before. While Nasreen's account clearly highlighted threats to self-esteem, that of Paramjit suggested that her sense of continuity (in particular, the continuity of valued relationships) was challenged as a result of her son's coming out. Incidentally, threats to continuity (of valued relationships) have also been observed in the accounts of British South Asian gay men, who fear irreversible negative changes to their relationship with their parents (Jaspal \& Siraj, 2011). Moreover, threats to continuity arose from fears surrounding their sons' future as gay men:

I was worried for the future because I am thinking that today he has told me he is gay.

Tomorrow he'll bring home a man. Then, he will want to get married. What will I tell the family? (Binder, female, Hindu, Indian)

Like Binder, several interviewees described the initial difficulties faced in learning of their sons' sexual orientation. A common strategy for coping was the hope that one's son's sexual orientation would eventually change and that he would become heterosexual. This strategy was severely undermined by the belief that the situation could 'escalate' in that they might find a same-sex partner and eventually wish to formalize their relationship. This was challenging for Binder because it could render her son's sexual orientation a public, rather than exclusively private, identity. She wished to 'contain' the threat by keeping this information between she and her son only. Indeed, several interviewees noted that it was impossible to undo one's coming out and that one's sexual orientation should therefore not be disclosed wider than one's immediate family. Given the importance appended to family honor ('izzat'), individuals expressed concerns about negative changes to valued relationships, namely with members of their extended family. Binder clearly perceived a threat to continuity because she had experienced negative change in the present but feared additional negativity in the future. She also feared negative changes in valued relationships.

In the participant sample, there was a more general concern about the possibility that the family's reputation might also be undermined:

My position in society will be nil if people find out the truth. (Sharandeep, female, Sikh, Indian)

How can I show my face in society? People will say I am a bad mother. What kind of sin has been happening in the family? They might think I accept this. I don't know. (Saqina, female, Muslim, Indian)

It is noteworthy that izzat was unanimously valued across the entire participant sample. Interviewees worried about how members of their respective ethno-cultural communities would respond to disclosure of their sons' sexual orientation. More specifically, Sharandeep 
and Saqina feared that their sons' sexual identity might be 'weaponized' against them in order to undermine both their identity as South Asian parents and the general social standing of their entire family within their respective communities. Muslim respondents were more inclined to regard homosexuality as a sin, which in turn shaped the nature of the threat to identity. Widespread knowledge of their son's sexual orientation could imply that parents themselves endorsed it and were, thus, complicit in this 'sinful' behavior. Several individuals felt that this could undermine their credibility in the community to the extent that it might no longer be possible to secure suitable marriage proposal for their other (heterosexual) children. Actual and anticipated threats to the self-esteem and continuity principles, in particular, led parents to attempt to cope.

\section{Denial as a strategy for coping with coming out}

Denial is a common deflection strategy for coping with identity threat. It enables the threatened individual to avoid exposure to identity threat because the threatening stimulus is simply not allowed to gain access to consciousness. Several individuals reported awareness of their sons' gender non-conformity during childhood, which sometimes roused suspicions about their non-heterosexual orientation. However, there was a tendency to deny this information:

When he was a child, I could see that something was not right with him and I didn't exactly know what it was but I could see that he was different from the other boys... I just closed my eyes to it and hoped he'd get better. (Lata, female, Hindu, Indian)

Lata construed her son's gender non-conformity as an anomaly and chose not to discuss this with her son, or even to acknowledge it, in the hope that 'he'd get better'. Interviewees referred to various perceived markers of gender non-conformity, such as exhibiting stereotypically feminine personality traits, not being keen on sports, exhibiting no romantic interest in girls. Crucially, Lata decided not only to avoid discussions of this topic with her son but also to avoid personal acknowledgement, as indicated by her metaphorical statement that she 'just closed [her] eyes to it'. On the one hand, the stigma and negativity surrounding her son's behavior and identity led to a silencing of the issue and, on the other hand, there was an implicit belief that silencing the issue would decrease the likelihood of it becoming a reality. Crucially, Lata continued to evaluate homosexuality negatively which was indicated by the notion that, by becoming heterosexual, her son would 'get better'. Some interviewees simply did not wish to accept the fact that their son was gay and, thus, denied this:

I was seeing lots of signs but none of them were registering. First, there were the 
magazines which were quite obvious. Then it was the people he brought back to the house. It was clear to me and us but I didn't want to think "my son is like that"... It just hurt. (Nazreen, female, Muslim, Pakistani)

Like Nazreen, most interviewees described encountering various signs that their child might be gay but many re-construed their meaning or significance as a means of denying their reality. Nazreen became suspicious about her son's sexual orientation due partly to the gay-themed magazines which she found in his room and to the people whom her son frequented. Although the signs were now considered 'quite obvious', at the time interviewees felt unable to derive conclusions from them because the information was too threatening to assimilate and accommodate in identity. Some interviewees acknowledged that they had often favored implausible explanations for these behaviors in order to avoid accepting the threatening reality. Like Lata, Nazarena appeared to harbor stigma in relation to her son's sexual orientation and referred to him as 'like that' rather than using the category 'gay'. In hindsight, Nazreen reported denying this information due to the psychological distress associated with its acceptance. Similarly, Paramjit reported rebuking her son for his sexual orientation without ever actually acknowledging his identity by category:

I shouted at him a lot, you know, in arguments, telling him "I know what you're doing" but I never said the word and one day he told me about himself and that's his life. The words didn't really make much sense for me then. I didn't want to hear this. (Paramjit, female, Sikh, Indian)

Paramjit clearly understood what her son was telling her because this corresponded to her own long-standing suspicions about his sexual orientation about which they habitually argued. However, she reported a preference for this not to be voiced in clear terms. This suggested that denial was her preferred strategy for coping with threat.

Some parents accepted and assimilated the information presented to them that their sons were gay, but appeared to deny the implications of this information. In other words, they failed to take any appropriate action on the basis of the information presented to them:

It was and still is to date the worst day of my life because all of my dreams were shattered that day... I talked to him about getting married but didn't really make the link in my head between what he told me and getting married. I suppose I thought if I carry on as normal, things will be normal. (Nasreen, female, Muslim, Pakistani) Nasreen construed her experience of her son's coming out as gay as threatening for identity. Like several respondents, Nasreen construed her son as a central component of identity and many of her 'dreams' and aspirations in life related to her son's future. Her son's 
coming out as gay was perceived to undermine these aspirations, thereby challenging the continuity principle of identity. Her strategy for coping with this threat to continuity focused on denying the relevance of her son's coming out. The information that her son was gay was assimilated but not quite accommodated in identity given that Nasreen continued to discuss the prospect of an arranged (heterosexual) marriage for her son. By her own admission, she failed to 'make the link' in her mind between her son's sexual orientation and the feasibility of a heterosexual marriage. In retrospect, Nasreen made sense of her behavior by noting that 'carrying on as normal' might lead to a new, more desirable reality - having a heterosexual son. This strategy was widespread in the participant sample:

We carried on as normal with my friends and the family. I went and bought all the wedding stuff. We told the family to keep a look out for suitable girls. I said to myself "OK, if he is gay, fine" but I was not going to change who I am because of this. (Ajay, male, Hindu, Indian)

He told me about himself and he wanted me to tell his dad but I refused. I didn't want everyone in the family to see him differently. (Salma, female, Muslim, Pakistani)

Parents may construe their sons' coming out as a threat to identity because this requires assimilation and accommodation of novel information in identity. Some perceive this as entailing a significant change to their identity. Ajay appeared to react defensively by refusing to change his plans and aspirations despite the novel information concerning his son's sexual orientation. Indeed, he reported continuing with his plans to find a female spouse for his son - even asking his extended family to 'keep a look out for suitable girls'. Furthermore, Salma sought to protect the continuity principle of identity by reducing the risk that others might view her son 'differently'. The desire to protect this identity principle led her to limit her son's coming out by excluding her husband and extended family. These examples demonstrate a complete disengagement from the reality of the situation - while cognisant of the facts, interviewees refused to acknowledge the implications of their sons' coming out.

\section{Isolation for avoiding social stigma}

Isolation is a coping strategy designed to protect identity from exposure to stigma. If the individual forms a protective layer around identity by avoiding contact with other people, the risk of threat is greatly reduced. Interviewees believed that they might be judged by members of the ethno-religious community and, thus, sought to maintain distance from them:

The first thing people will think is that it's the family that have done something. They are to blame. But how can we be to blame? It's the friendship circle, the mentality of 
the person actually. If they cannot control himself then it is his fault and the friends who are also at fault. (Paramjit, female, Sikh, Indian)

What did I do as a parent? The same food my other son received, he received. The same love, the same clothes. Why did he turn out like this and not Imran? (Salma, female, Muslim, Pakistani)

Respondents believed that they might be 'blamed' for their sons' sexual orientation and that community members might attribute their sons' sexual orientation to a flaw in their parenting style, for instance. Paramjit attributed her son's sexual orientation to the social environment, namely to her son's friendship circles, while Salma compared her gay son with her heterosexual son in order to distance his sexual orientation from her parenting style. The key point is that individuals feared others' reactions and, thus, attempted to demonstrate that they were not at fault. This led to scepticism about continued engagement with the ethnic ingroup.

In view of their concerns about their reputation in the community, parents of British South Asian young gay men expressed the fear that their sons' sexual orientation might become more widely known in their family and friendship circles. Some believed that news had already spread in their ethnic ingroup. Participants reported distancing themselves from friends and even family members in order to reduce the risk of exposure to social stigma:

When my son told me, I stopped going out to my friends' houses. Their sons were all getting married or engaged and I couldn't stand hearing questions about my son. I thought maybe they knew about this. It was a horrible feeling for me. (Abbas, male, Muslim, Pakistani)

Abbas experienced significant personal change when his son came out as gay because he felt compelled to sever ties with his close friends - this itself may constitute a threat to the continuity principle of identity. On the one hand, accounts of his friends' sons getting engaged and married were threatening for identity because they brought his own son's sexual orientation to the psychological forefront. Indeed, most participants reported a phase of denial following their sons' coming out. It is plausible to assume that hearing about others marital plans caused a threat to the continuity principle because it flagged up the rupture between his own past hopes and present reality.

As exhibited in Abbas' account, there was an element of social paranoia among interviewees many of whom irrationally believed that other community members knew about their sons' sexual orientation. For Abbas, this was 'horrible' because of the importance he clearly appended to his ethno-religious community and, crucially, to his family's standing 
within it. He and others frequently referred to izzat and the potential challenges that their son's coming out posed to it:

Before they asked me when he is getting married and I didn't like it. Now they don't ask me and I feel more scared that now they know he is not getting married and it makes me upset. I feel like they are talking about us behind my back and laughing at us. Now I don't like to see them or anyone. (Saqina, female, Muslim, Pakistani)

I had this feeling, this fear that everyone was talking about my son. If someone looked at him, I jumped to conclusions and just thought it was because he is gay... I preferred not to face people. I didn't want to hear anything. (Satpal, male, Sikh, Indian)

Saqina's account also exhibited an element of social paranoia. She construed the lack of marital enquiries from friends and family as evidence that they suspected that her son was gay. Saqina feared that her family was being talked about and laughed at, and that her family's standing in the community had been severely undermined by her son's coming out. It is easy to see how this could adversely impact the self-esteem principle of identity. However, there was in fact no evidence that her son's sexual orientation was widely known. It appeared that her own knowledge of this situation, following her son's coming out, led her to suspect that others too were aware of this information. Satpal acknowledged anticipating stigma from other people and recognized that he 'jumped to conclusions', attributing innocuous remarks from others to their knowledge of his son's sexual orientation. Several interviewees had reduced their level of interpersonal contact with others and preferred to avoid them in order to protect themselves from the stigma that they anticipated.

Isolation did appear to be a concern among participants, some of whom also imposed restrictions on their children in order to reduce the risk of social stigma:

If I could tie him up and keep him home, I would. I know he is making this lifestyle by going out with those friends of his. They're leading him into this world. (Sharandeep, female, Sikh, Indian)

I didn't want my other children bringing friends home because I didn't want people commenting on him or him to tell anyone. It was like I wanted to build a wall around my family and keep us out of the public view. (Mohammed, male, Muslim, Pakistani)

Sharandeep attributed her son's sexual orientation to the influence of her friends who she believed to be 'leading him into this world' and enabling him to 'build this lifestyle'. Homosexuality was construed as a behavior or lifestyle rather than as an orientation. Some individuals initially believed that it might be possible to intervene by stopping them from frequenting their gay friends. She and others essentially wished to isolate their sons from 
their friends' influence. Moreover, like Mohammed, some interviewees believed that it was essential to protect their family members from potential stigma associated with homosexuality. They perceived a risk that their other children might be taunted or ridiculed for having a gay brother. Indeed, Mohammed's strategy was to 'keep us out of public view' which he felt would protect family self-esteem. In short, as a coping strategy, isolation was widespread across the participant sample but also enacted in a variety of ways, including selfisolation and the imposition of isolation on one's gay son and on other members of the family. In most cases, the strategy was designed particularly to protect self-esteem.

\section{Discussion}

There is evidence that British South Asian gay men are at greater risk of parental stigma and rejection on the basis of their sexual orientation and that this is associated with poorer mental health outcomes in this population (Jaspal, Lopes \& Rehman, 2019). The present study is the first in the UK to examine parental reactions to British South Asian young men who come out as gay - from the perspective of British South Asian parents themselves. Through the lens of identity process theory, the impact for psychological wellbeing of having a son come out as gay and the coping strategies favored by British South Asian parents were explored.

Savin-Williams and Dube (1998) presented a developmental model of parental reactions to coming out, focusing on the following 'stages': shock, denial and isolation, anger, bargaining, depression and acceptance. The present study builds on this work by describing the ways in which parents' identity and psychological wellbeing might be compromised, what the barriers to acceptance might be, and how wellbeing might ultimately be enhanced among parents with gay sons. In a series of 'conversational enquiries', it was found that parents were especially susceptible to threats to the self-esteem and continuity principles of identity when their sons came out as gay, that they favored denial of their sons' sexual orientation, and that many deemed it necessary to isolate themselves from significant others in order to avoid social stigma. These observations suggest that coming out can be a psychological distressing for parents and that parents' coping responses may further undermine their psychological wellbeing.

\section{Stigma, threat and coping}

There is significant social stigma surrounding homosexuality in British South Asian communities. Indeed, one survey study revealed that only $43 \%$ of 2,001 British South Asians 
perceived same-sex relationships to be acceptable (BBC News, 2018). The survey found that older respondents were less likely to support same-sex relationships. Moreover, it is possible that even those respondents who indicate support for same-sex relationships may not manifest the same support when this concerns their own children. The first-hand accounts of British South Asian gay men themselves illustrate the social stigma that they face from within their ethno-religious communities, which can preclude coming out to significant others. In view of this pervasive social stigma, the parents of British South Asian gay men may also anticipate or be exposed to stigma due to their sons' sexual orientation.

Stigma in turn can undermine identity processes (Kaufman \& Johnson, 2004). Indeed, participants described threats to the self-esteem principle of identity because they believed that they and their immediate family members were derided for having failed as parents or as members of their religious ingroup. It is noteworthy that, as members of a collectivist culture, British South Asians tend to append importance to their ethnic and religious ingroups and that they seek validation from fellow members of these groups (Jaspal, 2015). These valued ingroups had a powerful effect on identity and wellbeing, and changes in one's relationship with these groups could pose threats to the continuity principle of identity.

Interviewees construed their sons' coming out as an undesirable change in their life narratives, which could result in adverse consequences for both their sons and their entire family unit. Although all of the participants had had time to reflect on their sons' coming out, none of them felt comfortable about their sons' sexual orientation and clearly experienced continued difficulties in assimilating and accommodating this in their own identities. They did not self-identify as parents of gay men and many refused to use the term 'gay' when describing their sons' sexual orientation. Several interviewees were fearful about involuntary disclosure of their sons' sexual orientation because of the implications that this could have for their social standing. Some expressed social paranoia and made 'sinister attributions' about the behavior of other members of their community (see Kramer, 2002), believing that an innocuous remark from a community member indicated their knowledge of their sons' sexual orientation.

In response to these threats to identity, individuals appeared to utilize maladaptive strategies for coping, namely denial and isolation. Several interviewees had noticed 'markers' of homosexuality in childhood, such as gender atypical behavior, but decided not to acknowledge these markers and, in some cases, actively attempted to attenuate them. Some parents responded to the initial coming out event with denial - they did not acknowledge, assimilate or accommodate the information being communicated to them. In addition to 
denial of the fact that one's son is gay, there was pervasive denial of the implications of having a gay son. Most respondents came to acknowledge and assimilate the coming out event but subsequently engaged in behaviors that suggested that they were in denial or that they were denying the significance of this information. In short, one's son's sexual orientation had not been accommodated in identity. For instance, some individuals continued to discuss arranged (heterosexual) marriage and to pursue marital offers on behalf of their sons. In reflecting on the reasons for engaging in denial, some parents expressed their refusal to 'change' their identities as a result of their sons' sexual orientation and instead decided to proceed as normal. They appeared to construe their sons' coming out as an 'imposition' on their own identities.

Isolation is a bedfellow of the denial strategy because by isolating oneself one minimizes the risk that others will raise topics that one would prefer not to acknowledge, assimilate or accommodate in identity (Breakwell, 1986). Several interviewees reported disengaging from their usual social circles - both as a means of averting identity threat and of minimizing its negative impact for wellbeing. This was clearly difficult given that these were previously valued personal relationships. However, this strategy was deemed preferable to the possibility of being exposed to stigma, questioned and judged.

Crucially, isolation functioned both at an individual level - some parents isolated themselves - and at a family level given that some refused to allow their immediate family members to frequent certain people or places or to invite others to the family home. These behaviors were designed to avoid involuntary disclosure of their sons' sexual orientation. Isolation can be an effective short-term strategy simply because it removes the risk of exposure to social stigma and, thus, identity threat. However, in the long term, it does preclude self-disclosure and access to social support, which conversely are effective coping strategies. There is evidence that community is important to first-generation British South Asians (Jaspal, 2015) but, in an attempt to protect identity from threat, individuals may deprive themselves of this important sense of community. It is easy to see how this can increase the risk of identity threat and decreased psychological wellbeing.

\section{Limitations and future research}

There are several limitations which should be addressed in future research. First, it is hoped that the data will be triangulated using other more generalizable research methods, such as quantitative survey methods, and with larger samples of participants. This might enable us to generalize findings beyond the participant sample. Second, as this study focused 
only on the parents of gay men, there is a need to capture parental reactions of other sexual minority groups, such as lesbian women and bisexual men and women. It is possible that parental experiences and reactions and, thus, recommendations for the parents of other sexual minority groups will differ in these populations. Third, this study focused on British South Asians. Thus, other ethnic minority communities in the UK, such as Bangladeshis, Africans and Latin Americans, should be the focus of future research as it is possible that there are distinct challenges faced by parents in these communities. It is hoped that this study will kickstart a programme of research into the identities and psychological wellbeing of parents of sexual minority individuals.

\section{Recommendations for enhancing identity and wellbeing}

Notwithstanding these limitations, the findings from this study offer some recommendations for supporting the parents of British South Asian young men who come out as gay.

First, support groups and networks which exist for the parents of men and boys who come out as gay should acknowledge the cultural, ethnic and religious diversity of parents in this situation, and seek to provide opportunities for acknowledging and discussing the unique challenges faced by members of these minority groups. It would be beneficial to facilitate the establishment of support groups that focus on specific minority identities, given that participants in this study appeared to be devoid of any social support and relied almost entirely on denial and isolation. Parents may benefit from 'safe' spaces in which they can self-disclose, exchange confidences and seek support.

Second, having a son come out as gay should be acknowledged as a potential risk factor for decreased psychological wellbeing among members of communities in which there is significant stigma surrounding, and limited acknowledgement of, homosexuality. Although some parents may locate the 'problem' within the sexual orientation of their sons, they must be supported to understand the social, cultural and psychological underpinnings of social stigma. Moreover, they should be offered effective psychological support for reducing the risk to their psychological wellbeing. Psychotherapeutic approaches, such as cognitive behavioral therapy and the humanistic person-centred approach, may be used to equip British South Asian parents with the skills, resources and resilience to cope more effectively with their sons' coming out.

Third, there is clearly a need to engage with the British South Asian community concerning the reality of sexual diversity and the presence of gay, lesbian, bisexual and other 
sexual minority individuals in society, including their own communities. In the UK, there has been resistance to sexual diversity in British South Asian communities (e.g. Ferguson, 2019), but some persistence is required for social change to come about. Increased awareness and understanding of sexual diversity would make it easier for parents to understand and potentially accept the gay identity of a son. Stigmatizing images and representations of sexual minorities must be challenged. It would be beneficial to use outreach to engage communities in discussions concerning sexual diversity.

Fourth, this study and future research into parental reactions to coming out in this population could inform the composition of a self-help guide for parents. Such a guide could be useful in empowering parents to accept and understand the coming out event, to cope with it effectively, and to communicate about it to significant others, including their gay sons. This study revealed that interpersonal relations between parents and their sons were characterized by silence and stigma. Crucially, a self-help guide for parents would need to be based on empirical evidence, such as that presented in this article, and be linguistically an culturally accessible to parents from South Asian communities. It is therefore suggested that future research to continue to engage with this important topic and to advocate for positive social change for British South Asian gay men and indeed their parents.

\section{REFERENCES}

Anderson, E. (2010). "At least with cheating there is an attempt at monogamy": Cheating and monogamism among undergraduate heterosexual men. Journal of Social and Personal Relationships, 27(7), 851-872. https://doi.org/10.1177/0265407510373908

Bassi, Camila (2008). "The precarious and contradictory moments of existence for an emergent British Asian gay culture." In Dwyer, C and Bressey, C (eds.) New Geographies of Race and Racism (pp. 209-222). Farnham: Ashgate.

BBC News (2018). British Asians more socially conservative than rest of UK, survey suggests. BBC News. 13 August 2018. http://www.bbc.co.uk/news/uk-45133717 Accessed 20 June 2019.

Bhugra, D. (1997). Coming out by South Asian gay men in the United Kingdom. Archives of Sexual Behavior, 26(5), 547-557. http://dx.doi.org/10.1023/A:1024512023379

Braun, V. \& Clark, V. (2006). Using thematic analysis in psychology. Qualitative Research in Psychology, 3, 77-101. http://dx.doi.org/10.1191/1478088706qp063oa

Breakwell, G.M. (1986). Coping with Threatened Identities. London: Methuen. 
D’Amico, E., Julien, D., Tremblay, N. \& Chartrand, E. (2015). Gay, lesbian, and bisexual youths coming out to their parents: Parental reactions and youths' outcomes, Journal of GLBT Family Studies, 11(5), 411-437. https://doi.org/10.1080/1550428X.2014.981627

D’Augelli, A.R., Grossman, A.H., Salter, N.P., Vaseyt, J.J., Starks, M.T. \& Sinclair, K.O. (2005). Predicting the suicide attempts of lesbian, gay and bisexual youth. Suicide and Life-Threatening Behavior, 35(6), 646-660. https://doi.org/10.1521/suli.2005.35.6.646

D’Augelli, A.R., Grossman, A.H. \& Starks, M.T. (2008). Families of gay, lesbian, and bisexual youth: What do parents and siblings know and how do they react? Journal of GLBT Family Studies, 4, 95-115. https://doi.org/10.1080/15504280802084506

Duran, K. (1993). Homosexuality in Islam. In A. Swidler (Ed.), Homosexuality and World Religions (pp. 181-198). Harrisburg, PA: Trinity Press.

Ferguson, D. (2019). 'We can't give in': The Birmingham school on the frontline of anti-LGBT protests. The Guardian, 26 May 2019 https:/www.theguardian.com/uknews/2019/may/26/birmingham-anderton-park-primary-muslim-protests-lgbt-teaching-rights Accessed 20 June 2019.

Gertler, L.M. (2014). The coming out experience, internalized homophobia and selfcompassion in LGBQ young adults. Unpublished PsycD thesis, The Wright Institute, Berkeley, USA.

Ghuman, P. (2003). Double loyalties: South Asian adolescents in the West. Cardiff: University of Wales Press.

Jaspal, R. (2010). Identity threat among British Muslim gay men. The Psychologist, 23(8), 640-41. https://thepsychologist.bps.org.uk/volume-23/edition-8/identity-threat-amongbritish-muslim-gay-men

Jaspal, R. (2012). "I never faced up to being gay”: Sexual, religious and ethnic identities among British South Asian gay men. Culture, Health and Sexuality: An International Journal for Research, Intervention and Care, 14(7), 76780. https://doi.org/10.1080/13691058.2012.693626

Jaspal, R. (2014). Arranged marriage, identity and psychological wellbeing among British Asian gay men. Journal of GLBT Family Studies, 10(5), 425448. https://doi.org/10.1080/1550428X.2013.846105

Jaspal, R. (2015). Migration and identity processes among first generation British South Asians. South Asian Diaspora, 7(2), 79-96. https://doi.org/10.1080/19438192.2015.1007634 
Jaspal, R. \& Breakwell, G.M. (Eds.) (2014). Identity Process Theory: Identity, Social Action and Social Change. Cambridge: Cambridge University Press.

Jaspal, R. \& Cinnirella, M. (2010). Coping with potentially incompatible identities: accounts of religious, ethnic and sexual identities from British Pakistani men who identify as Muslim and gay. British Journal of Social Psychology, 49(4), 849-870.

https://doi.org/10.1348/014466609X485025

Jaspal, R. \& Cinnirella, M. (2012). Identity processes, threat and interpersonal relations: accounts from British Muslim gay men. Journal of Homosexuality, 59(2), 215-40. https://doi.org/10.1080/00918369.2012.638551

Jaspal, R., Lopes, B. \& Rehman, Z. (2019). Depressive psychopathology in Black \& Minority Ethnic gay, lesbian and bisexual people in the UK. Paper presented at the 33rd Annual Conference of the European Health Psychology Society, Dubrovnik, Croatia, 6 September 2019. https://2019.ehps.net/wpcontent/uploads/2019/08/EHPS_2019 Program_09Aug.pdf

Jaspal, R. \& Siraj, A. (2011). Perceptions of 'coming out' among British Muslim gay men. Psychology and Sexuality, 2(3),183-197. https://doi.org/10.1080/19419899.2010.526627

Kaufman, J.M. \& Johnson, C. (2004). Stigmatized individuals and the process of identity. The Sociological Quarterly, 45(4), 807-833. https://doi.org/10.1111/j.15338525.2004.tb02315.x

Kramer, R.M. (2002). When paranoia makes sense. Harvard Business Review, 80(7), 62-9. https://hbr.org/2002/07/when-paranoia-makes-sense

Livingston, J. \& Fourie, E. (2016). The experiences and meanings that shape heterosexual fathers' relationships with their gay sons in South Africa. Journal of Homosexuality, 63(12), 1630-1659. https://doi.org/10.1080/00918369.2016.1158009

Lyons, E. \& Coyle, A. (Eds.) (2007). Analysing Qualitative Data in Psychology. London: Sage.

McCormack, M. (2012). The Declining Significance of Homophobia: How Teenage Boys are Redefining Masculinity and Heterosexuality. Oxford: Oxford University Press.

Salway, T., Plöderl, M., Liu, J. \& Gustafson, P. (2019). Effects of multiple forms of information bias on estimated prevalence of suicide attempts according to sexual orientation: An application of a Bayesian misclassification correction method to data from a systematic review. American Journal of Epidemiology, 188(1), 239-249.

https://doi.org/10.1093/aje/kwy200 
Saunders, B., Sim, J., Kingstone, T., Baker, S., Waterfield, J., Bartlam, B., ... Jinks, C. (2018). Saturation in qualitative research: Exploring its conceptualization and operationalization. Quality and Quantity, 52(4), 1893-1907. https://doi.org/10.1007/s11135$\underline{017-0574-8}$

Savin-Williams, R.C. \& Dube, E.M. (1998). Parental reactions to their child's disclosure of a gay/lesbian identity. Family Relations, 47, 1-7. http://dx.doi.org/10.2307/584845

UK Census (2011). Population of England and Wales. https://www.ethnicity-factsfigures.service.gov.uk/uk-population-by-ethnicity/national-and-regionalpopulations/population-of-england-and-wales/latest Accessed 20 June 2019.

Vignoles, V. (2014). Quantitative approaches to researching identity processes and motivational principles. In R. Jaspal \& G.M. Breakwell (eds.) Identity Process Theory: Identity, Social Action and Social Change (pp.65-94). Cambridge: Cambridge University Press.

Willoughby, B.L.B., Malik, N.M. \& Lindahl, K.M. (2006). Parental reactions to their sons' sexual orientation disclosures: The roles of family cohesion, adaptability, and parenting style. Psychology of Men \& Masculinity, 7(1), 14-26. http://dx.doi.org/10.1037/1524$\underline{9220.7 .1 .14}$

Yip, A.K.T. (2004). Embracing Allah and sexuality? South Asian non-heterosexual Muslims in Britain. In K.A. Jacobsen \& P.P. Kumar (Eds.), South Asians in the Diaspora: Histories and Religious Traditions (pp. 294-310). Leiden: Brill.

Yip, A.K.T. (2007). Sexual orientation discrimination in religious communities. In M.V.L. Badgett \& J. Frank (Eds.), Sexual Orientation Discrimination: An International Perspective (pp. 209-244). London: Routledge. 